\title{
Scope and Limitations on the Site-selective Cross-couplings of Arylzincs with 2,3- and 2,5-Dibromothiophene
}

\author{
Hyun-Hee Cho and Seung-Hoi Kim* \\ Department of Chemistry, Dankook University, Cheonan 330-714, Korea.*E-mail: kimsemail@dankook.ac.kr \\ Received April 23, 2014, Accepted June 3, 2014
}

Key Words : Site-selectivity, Organozinc, Cross-coupling, Dibromothiophene

Cross-coupling reactions of organometallic reagents have been considered to be one of the most efficient synthetic systems for the preparation of organic functional materials. ${ }^{1}$ To furnish up this strategy, installing various functionalities into the core moiety has played a huge role in the efficient synthesis of the valuable organic complexes. Notwithstanding the significance and effectiveness, this approach has encountered a few difficulties, which should be resolved.

In most of the previous works exploring the synthetic utilities of transition-metal chemistry, multiple-halogenated aryl and/or heteroaryl compounds have frequently been used as the core molecules. As easily noticed, multi-halogenated heterocyclic compounds generally contain equivalent and/ or pseudo-equivalent multiple halogen atoms, and, more significantly, those halogens possess different chemical properties. ${ }^{2}$ Owing to this natural instinct, selectivity has been a serious issue in the course of cross-coupling reactions with organometallic reagents, and these aspects have been profoundly reviewed. ${ }^{2}$ Among the many poly-halogenated heterocyclic compounds, we were particularly interested in thiophene systems, because poly-functionalized thiophene derivatives have been utilized for the preparation of valuable functional complexes with a wide range of applications, such as in optoelectrochemical materials, pharmaceuticals, and biologically active molecules. ${ }^{3}$ Once again, cross-coupling reactions of organometallics with multiple halogensubstituted thiophene derivatives were the most popular subjects, and large numbers of energetic protocols have been developed to fulfill the potential demand for the multisubstituted thiophenes. ${ }^{4}$

Of those developed, 2,3- and 2,5-dibromothiophenes are typically more suitable molecules for investigating the selectivity in cross-coupling reactions with organometallics due to the chemical similarity of the two $\mathrm{C}-\mathrm{Br}$ bonds presented in the thiophene molecular structure. ${ }^{5}$ However, a relatively limited number of examples of the site-selective coupling reaction of these compounds have been established, presumably, because of their low selectivity. ${ }^{6}$ Rasmussen et al. demonstrated the regioselectivity of the Negishi coupling with tribromothiophene based on steric versus electronic effects. ${ }^{7}$ A recent work by Staubitz's group showed a very interesting dual selectivity with the 2,5-dimetallic thiophene compound. ${ }^{8 \mathrm{a}, \mathrm{b}}$

As part of our efforts to determine the scope and limita- tions of utilizing organozinc reagents in cross-coupling reactions, especially on the regio-selectivity, the coupling reactions of various organozinc reagenst with 2,3- and 2,5-dibromothiophene were examined in this study.

To examine the site-selectivity, we first began with 2,3dibromothiophene (I) bearing two chemically pseudo-equivalent carbon-bromine bonds. As described in Table 1, a $\mathrm{Pd}(\mathrm{II})$-catalytic system in THF at room temperature was chosen, since it worked effectively to give rise to the coupling product in previous reports. ${ }^{8 \mathrm{f}}$ The organozinc reagents used in this study were prepared by the direct oxidative addition of highly active zinc. ${ }^{9}$

${ }^{1} \mathrm{H}$ NMR analysis of the products clearly showed that

Table 1. Coupling reactions with 2,3-dibromothiophene (I)

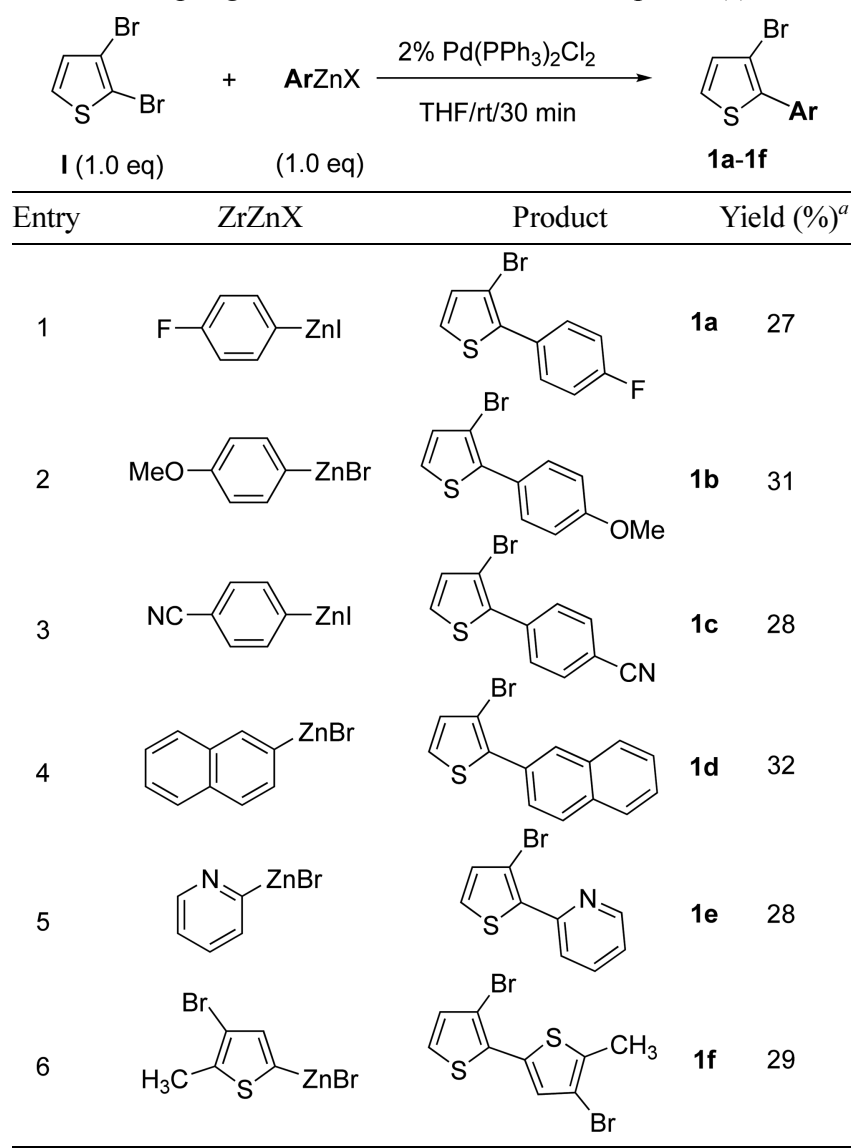

$a_{\text {isolated yield }}$ 
Table 2. Catalyst-screening with 2,5-dibromothiophene (II)

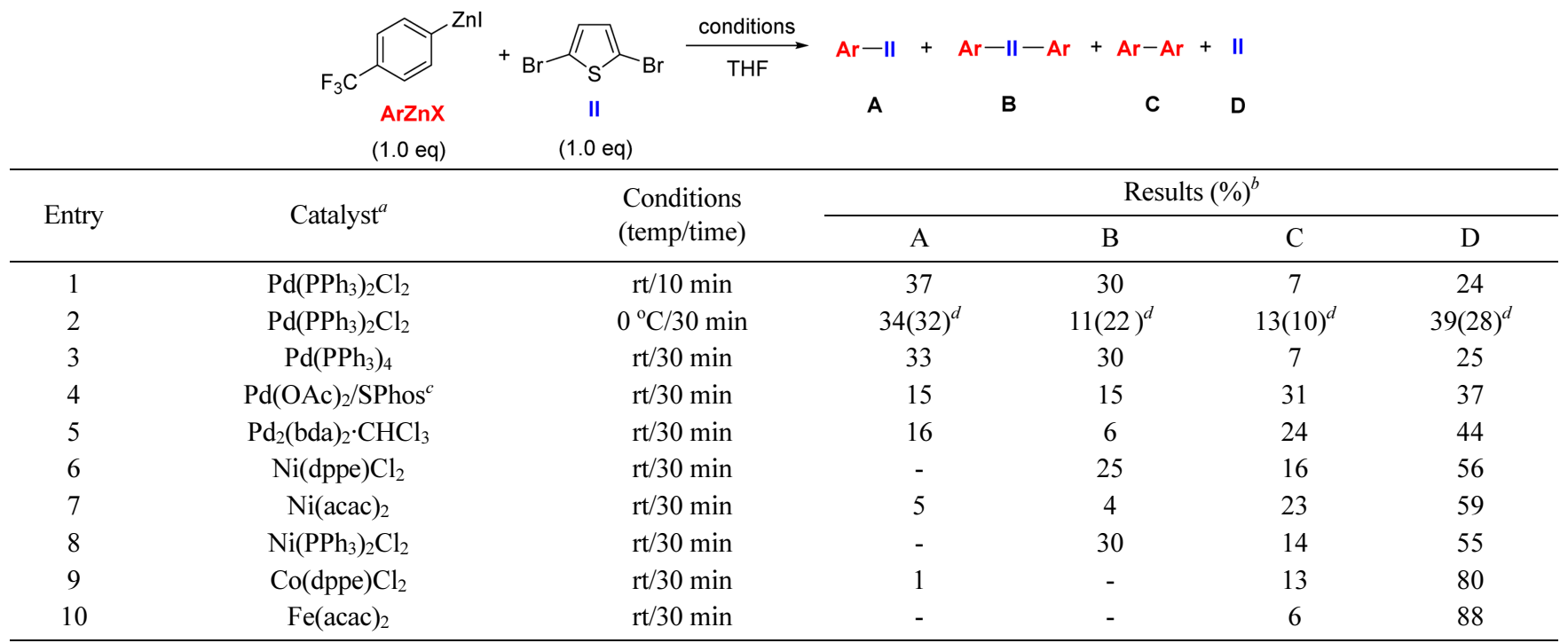

${ }^{a} 2 \mathrm{~mol} \%$ used otherwise mentioned. ${ }^{b}$ calculated based on the area ratios of GC-MS analysis. ${ }^{c} 4 \mathrm{~mol} \%$ used. ${ }^{d} 0{ }^{\circ} \mathrm{C}$ for $2 \mathrm{~h}$

coupling took placed at the 2-bromine position, leaving the other bromine at the 3 -position intact. Two doublet signals $(J$ $=5.0 \mathrm{~Hz})$ at $7.10 \mathrm{ppm}$ and $7.38 \mathrm{ppm}$ on ${ }^{1} \mathrm{H}$ spectrum attributed to the $\mathrm{C} 4$ and $\mathrm{C} 5$ hydrogens of thiophene ring, respectively, were consistently observed in the obtained products shown in Table 1. This observed selectivity was essentially in agreement with the NMR-based prediction. ${ }^{5}$ Along with the selectivity originating from the electronic effect, steric impacts also had a decisive influence on the isolated yield. Even though the corresponding coupling products were obtained in low yields, partially due to low progress of the cross-coupling reaction or homo-coupling of organozinc, no further effort for optimization was made, as it was not the main objective of this study (Table 1).

An intensive evaluation of the selectivity has been accomplished with 2,5-dibromothiophene, possessing two identical carbon-bromine bonds. Owing to its chemical homogeneity, obtaining selectivity would be more challenging, as well as more attractive. Prior to performing a series of coupling reactions, a catalyst-screening test was first performed, for which the results are summarized in Table 2.

4-Trifluoromethylphenylzinc iodide (1.0 equivalent) was coupled with 1.0 equivalent of 2,5-dibromothiophene (II) under appropriate conditions depicted in Table 2. From the first two examinations carried out with $\mathrm{Pd}(\mathrm{II})$-catalyst (entries 1 and 2, Table 2), it could be concluded that the reaction time and temperature were not critical for determination of both selectivity and reaction progress. Therefore, the rest of the reactions were conducted at room temperature, and the progress was monitored for $30 \mathrm{~min}$. There was a general trend for higher production of both mono-coupled product (A) and di-coupled product (B) by use of $\mathrm{Pd}\left(\mathrm{PPh}_{3}\right)_{2} \mathrm{Cl}_{2}$ and $\mathrm{Pd}\left(\mathrm{PPh}_{3}\right)_{4}$-catalysts, compared to the other catalysts used. Interestingly, the reaction progress was a lot slower when both $\mathrm{Pd}(\mathrm{OAc})_{2} / \mathrm{SPhos}$ and $\mathrm{Pd}_{2}(\mathrm{bda})_{2} \cdot \mathrm{CHCl}_{3}$ were employed (entries 4 and 5, Table 2). ${ }^{10}$ Applying Ni-catalyst led to more production of homo-coupled and di-coupled products than cross-coupled ones with low progress (entries 6-8, Table 2). $\mathrm{Co}-$ and Fe-catalysts turned out to be ineffective in the coupling reaction (entries 9 and 10, Table 2).

As depicted in Table 2, $\mathrm{Pd}\left(\mathrm{PPh}_{3}\right)_{2} \mathrm{Cl}_{2}$ was regarded as an appropriate catalyst to examine the selectivity in the organozinc coupling with 2,5-dibromothiophene. For convenience, all the reactions for this catalyst were conducted at room temperature for $30 \mathrm{~min}$.

The outcomes obtained from the early catalyst-screening test were enough to anticipate the formation of products consisting of both mono-substituted thiophenes (A, Table 3) and di-substituted thiophenes (B, Table 3 ). This prediction was further confirmed by the analysis of the final products purified using a column chromatography (2\% EtOAc/98\% Hexanes as eluent). As described in Table 3, no specific trend of the selectivity depending on the functionality on the organozincs was observed. Instead, according to the ratios of $\mathbf{A}$ and $\mathbf{B}$ in Table 3, it could be inferred that mono-substitution was a little more favor over di-substitution (entries 1, 9 and 10, Table 3). In most of the cases, the formation of di-coupling products was detected by both TLC and GCMS. However, the purification procedure was carried out in limited reactions only.

Next, we applied the scope and limitations examined in this study to make a variety of 2,5-disubstituted thiophene derivatives. Based on the data above, the first step was to prepare more thiophene derivatives. As can be seen in Figure 1, 2,5-dibromothiophenes were reacted with excess amounts of 2- or 3-pyridylzinc bromide in the presence of $\mathrm{Pd}\left(\mathrm{PPh}_{3}\right)_{2} \mathrm{Cl}_{2}$. The coupling was completed in $24 \mathrm{~h}$ at refluxing temperature. Two bromine atoms were successfully substituted with the corresponding heteroaryl molecules through this protocol giving rise to 4, 5, and $\mathbf{6}$ in Figure 1.

Interestingly, the residual bromine atom on the product obtained from mono-substitution of 2,5-dibromothiophene 
Table 3. Coupling of arylzincs with 2,5-dibromothiophene (II)

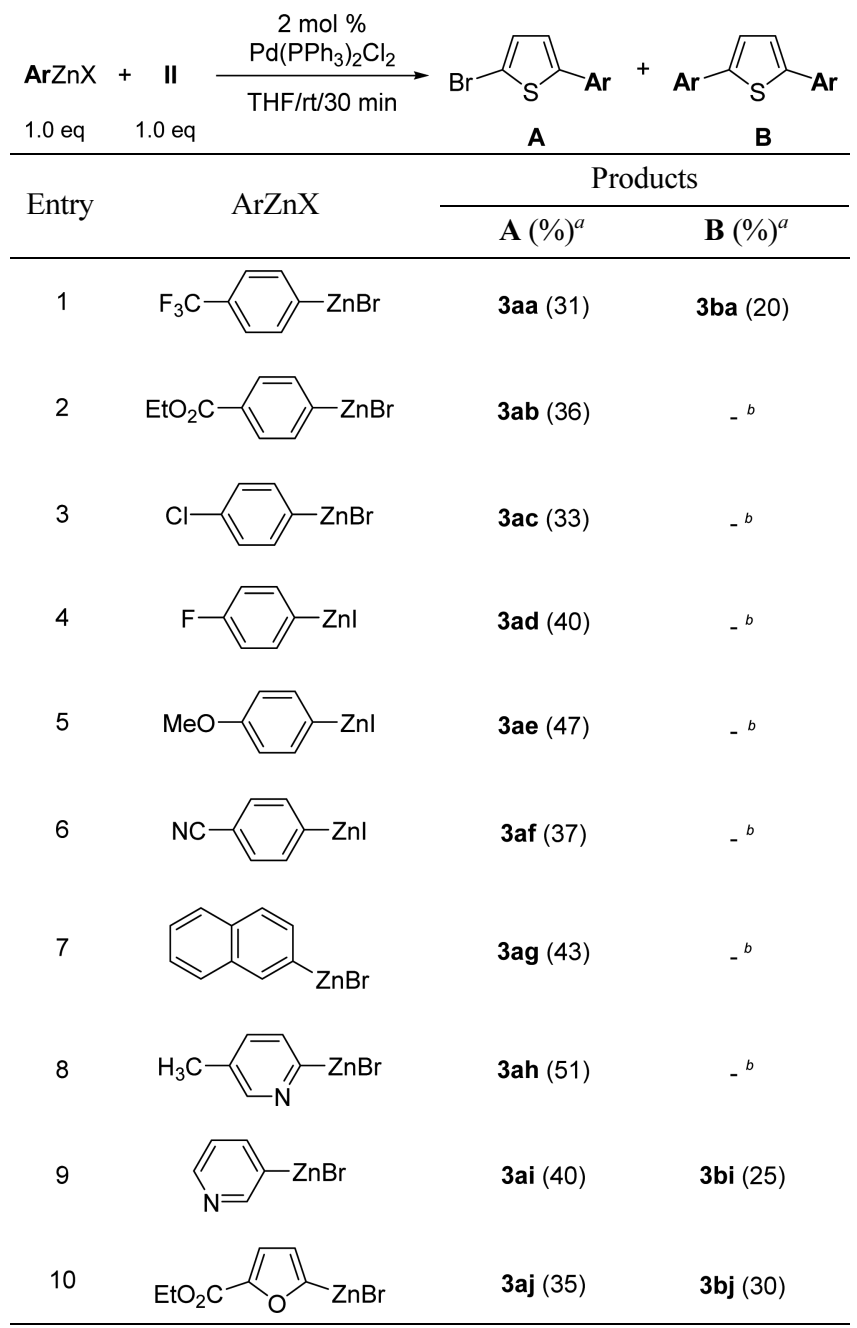

aisolated yield (based on II). ${ }^{b}$ not isolated
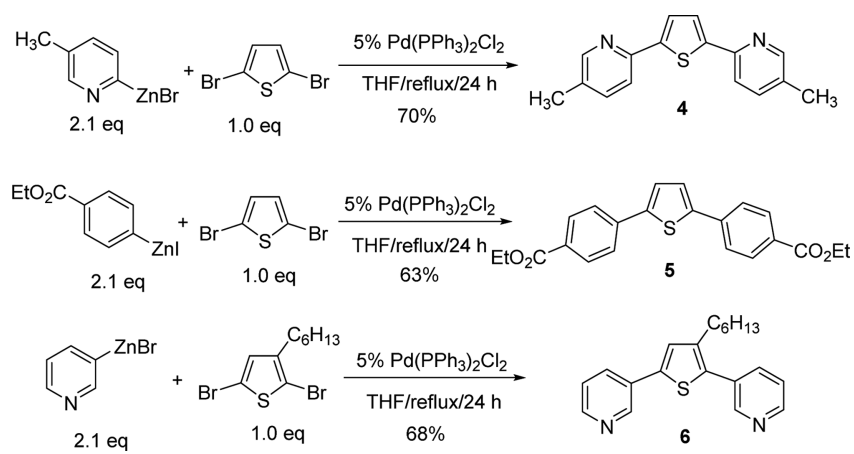

Figure 1. Di-coupling of 2,5-dibromothiophenes in one-pot reaction.

also had good functionality, and could be replaced by a consecutive coupling reaction with an organozinc. This strategy could be a facile synthetic tool for the preparation of unsymmetrically 2,5-disubstituted thiophenes. The examples are shown in Figure 2, and the coupling products ( 7 and $\mathbf{8}$ ) were obtained in $80 \%$ and $77 \%$ isolated yields, respectively.

In conclusion, site-selectivity in the cross-coupling reactions of arylzinc reagents with both 2,3-dibromothiophene

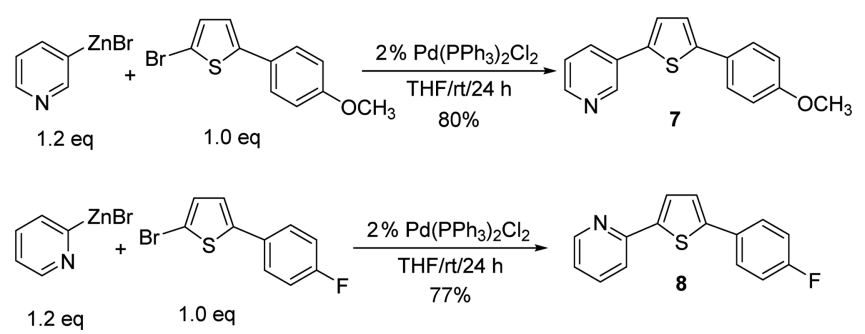

Figure 2. Unsymmetrically di-substituted thiophenes.

(I) bearing pseudo-identical carbon-bromine bonds, and symmetrically halogenated 2,5-dibromothiophene (II), have been investigated. ${ }^{11} \mathrm{~A}$ high preference for the mono-crosscoupling reaction with $\mathbf{I}$ at the C2-position was obtained whereas a moderate selectivity was observed for the coupling reactions with II. In addition, multi-substituted thiophene derivatives were also successfully prepared utilizing this methodology.

\section{References}

1. For recent monographs, see: (a) Organotransition Metal Chemistry: from bonding to catalysis; Hartwig, J., Ed.; University Science Books: California, 2009. (b) Organometallics in Synthesis, A Manual, 2nd ed.; Schlosser, M., Ed.; John Wiley \& Sons: LTD. Switzerland, 2002.

2. For reviews: (a) Schröter, S.; Stock, C.; Bach, T. Tetrahedron 2005, 61, 2245. (b) Chelucci, G. Chem. Rev. 2012, 112, 1344. For recent examples: (c) Ahmed, S.; Sharif, M.; Shoaib, K.; Reimann, S.; Iqbal, J.; Patonay, T.; Spannenberg, A.; Langer, P. Tetrahedron Lett. 2013, 54, 1669. (d) Akrawi, O. A.; Khan, A.; Hussain, M.; Mohammed, H. H.; Villinger, A.; Langer, P. Tetrahedron Lett. 2013, 54, 3037. (e) Khaddour, Z.; Eleya, N.; Akrawi, O. A.; Hamdy, A. M.; Patonay, T.; Villinger, A.; Langer, P. Tetrahedron Lett. 2013, 54, 5201 (f) Ibad, M. F.; Zinad, D. S.; Hussain, M.; Ali, A.; Villinger, A.; Langer, P. Tetrahedron 2013, 69, 7492. (g) Chang, J. H.; Kang, H. U.; Jung, I. H.; Cho. C. G. Org. Lett. 2010, 12, 2016.

3. (a) Handbook of Conducting Polymers, 3rd ed.; Skotheim, T. A., Reynolds, J. R., Eds.; CRC Press: Boca Raton, FL, 2007. (b) Handbook of Oligo- and Polythiophenes; Fichou, D., Ed.; WileyVCH: Weinheim, 1999. (c) Bohlmann, F.; Zdero, C. In Thiophene and its Derivatives; Gronowitz, S., Ed.; The Chemistry of Heterocyclic Compounds, vol. 44, part 1, Wiley \& Sons: New York, 1985; pp 261-323. (d) Press, J. B. In Thiophene and its Derivatives; Gronowitz, S., Ed.; The Chemistry of Heterocyclic Compounds, Vol. 44, Wiley \& Sons: New York, 1991; pp 397-502.

4. (a) Wang, J.-R.; Manabe, K. Synthesis 2009, 9, 1405. (b) Fairlamb, I. J. S. Chem. Soc. Rev. 2007, 36, 1036. (c) Christophersen, C.; Begtrup, M.; Ebdrup, S.; Petersen, H.; Vedsø, P. J. Org. Chem. 2003, 68, 9513. (d) Ogawa, K.; Rasmussen, S. C. J. Org. Chem. 2003, 68, 2921. (e) Pereira, R.; Iglesias, B.; de Lera, A. R. Tetrahedron 2001, 57, 7871. (f) Yamazaki, T.; Murata, Y.; Komatsu, K.; Furukawa, K.; Morita, M.; Maruyama, N.; Yamao, T.; Fujita, S. Org. Lett. 2004, 6, 4865. (g) Dang, T. T.; Rasool, N.; Dang, T. T.; Reinke, H.; Langer, P. Tetrahedron Lett. 2007, 48, 845.

5. For a simple prediction of site-selectivity based on NMR study, see: Handy, S. T.; Zhang, Y. Chem. Commun. 2006, 299.

6. Tranchier, J.-P.; Chavignon, R.; Prim, D.; Auffrant, A.; Plyta, Z. F.; Rose-Munch, F.; Rose, E. Tetrahedron Lett. 2000, 41, 3607.

7. Amb, C. M.; Rasmussen, S. C. Eur. J. Org. Chem. 2008, 801.

8. (a) Heinrich, A. C. J.; Thiedemann, B.; Gates, P. J.; Staubitz, A. Org. Lett. 2013, 18, 4666. (b) Linshoeft, J.; Heinrich, A. C. J.; 
Segler, S. A. W.; Gates, P. J.; Staubitz, A. Org. Lett. 2012, 14, 5644. For more examples for thienylmetallics. (c) Iida, T.; Wada, T.; Tomimoto, K.; Mase, T. Tetrahedron Lett. 2001, 42, 4841. (d) Abarbri, M.; Thibonnet, J.; Berillon, L.; Dehmel, F.; Rottlander, M.; Knochel, P. J. Org. Chem. 2000, 65, 4618. (e) Abarbri, M.; Dehmel, F.; Knochel, P. Tetrahedron Lett. 1999, 40, 7449. (f) Jung, H. S.; Cho, H. H.; Kim, S. H. Tetrahedron Lett, 2013, 54, 960.

9. Preparation and utilization of highly active zinc, see: Rieke, R. D.; Hanson, M. V.; Brown, J. D. J. Org. Chem. 1996, 61, 2726.

10. Ligand effect on the coupling reaction was described in reference

11. Representative procedures: (a) Preparation of 4-(3-bromothiophen2-yl)benzonitrile (1c); Into a $25 \mathrm{~mL}$ round-bottomed flask were added $\mathrm{Pd}\left(\mathrm{PPh}_{3}\right)_{2} \mathrm{Cl}_{2}(0.02 \mathrm{~g}, 2.0 \mathrm{~mol} \%)$, 2,3-dibromothiophene $(0.97 \mathrm{~g}, 4.0 \mathrm{mmol})$ and $12.0 \mathrm{~mL}$ of (4-cyanophenyl)zinc chloride (0.45 $\mathrm{M}$ in THF, $5.0 \mathrm{mmol}$ ) under an argon atmosphere at room temperature. The resulting mixture was stirred at room temper- ature for $30 \mathrm{~min}$. Quenched with $3 \mathrm{M} \mathrm{HCl}$ solution, then extracted with ethyl ether $(10 \mathrm{~mL} \times 3)$. Washed with saturated $\mathrm{NaHCO}_{3}$, $\mathrm{Na}_{2} \mathrm{~S}_{2} \mathrm{O}_{3}$ solution and brine, then dried over anhydrous $\mathrm{MgSO}_{4}$ Purification by column chromatography on silica gel ( $1 \%$ ethyl acetate $/ 99 \%$ heptane) afforded $0.30 \mathrm{~g}$ of $1 \mathbf{c}$ in $28 \%$ isolated yield as a yellow solid (mp $\left.107-108{ }^{\circ} \mathrm{C}\right) ;{ }^{1} \mathrm{H} \mathrm{NMR}\left(\mathrm{CDCl}_{3}, 500 \mathrm{MHz}\right) \delta$ $7.78(\mathrm{~d}, J=10.0 \mathrm{~Hz}, 2 \mathrm{H}), 7.71(\mathrm{~d}, J=10.0 \mathrm{~Hz}, 2 \mathrm{H}), 7.38(\mathrm{~d}, J=$ $5.0 \mathrm{~Hz}, 1 \mathrm{H}), 7.10(\mathrm{~d}, J=5.0 \mathrm{~Hz}, 1 \mathrm{H}) ;{ }^{13} \mathrm{C}$ NMR $\left(\mathrm{CDCl}_{3}, 125\right.$ MHz) $\delta 137.5,135.9,132.3,129.4,126.7,118.7,111.7,109.1$. (b) preparation of 4-(5-bromothiophen-2-yl)benzonitrile (3af); carried out in a similar manner as above. Purification by column chromatography on silica gel ( $2 \%$ ethyl acetate $/ 98 \%$ hexanes) afforded 0.39 g of $\mathbf{3 a f}$ in 37\% isolated yield as a creamy white solid ( $\mathrm{mp}$ 91-92 $\left.{ }^{\circ} \mathrm{C}\right) ;{ }^{1} \mathrm{H} \mathrm{NMR}\left(\mathrm{CDCl}_{3}, 500 \mathrm{MHz}\right) \delta 7.65(\mathrm{~d}, J=10.0 \mathrm{~Hz}, 2 \mathrm{H}), 7.59$ $(\mathrm{d}, J=10.0 \mathrm{~Hz}, 2 \mathrm{H}), 7.17(\mathrm{~s}, 1 \mathrm{H}), 7.09(\mathrm{~s}, 1 \mathrm{H}) ;{ }^{13} \mathrm{C} \mathrm{NMR}\left(\mathrm{CDCl}_{3}\right.$, $125 \mathrm{MHz}) \delta 143.4,137.8,132.9,131.4,125.8,125.3,118.7$, $114.2,111.0$. 